\title{
First in-human radiation dosimetry of the gastrin-releasing peptide (GRP) receptor antagonist ${ }^{68} \mathrm{Ga}$-NODAGA-MJ9
}

Silvano Gnesin ${ }^{1 *}$ (D), Francesco Cicone ${ }^{2}$, Periklis Mitsakis², Axel Van der Gucht², Sébastien Baechler ${ }^{1}$, Raymond Miralbell ${ }^{3}$, Valentina Garibotto ${ }^{4}$, Thomas Zilli ${ }^{3}$ and John O. Prior ${ }^{2}$

\begin{abstract}
Background: Gastrin-releasing peptide receptor antagonists have promise in theranostics of several highly incident tumours, including prostate and breast. This study presents the first human dosimetry of ${ }^{68} \mathrm{Ga}$-NODAGA-MJ9 in the first five consecutive patients with recurrent prostate cancer included in a dual-tracer positron emission tomography (PET) protocol. Five male patients with biochemical relapse of prostate adenocarcinoma underwent four whole-body time-of-flight PET/CT scans within $2 \mathrm{~h}$ after tracer injection. To be used as input in OLINDA/EXM 2. 0 , time-integrated activity coefficients were derived from manually drawn regions of interest over the following body regions: brain, thyroid, lungs, heart, liver, gallbladder, spleen, stomach, kidneys, adrenals, red marrow, pancreas, intestines, urinary bladder and whole body. Organ absorbed doses and effective dose (ED) were calculated with OLINDA/EXM 2.0 using the NURBS voxelized phantoms adjusted to the ICRP-89 organ masses and ICRP103 tissueweighting factors. Additional absorbed dose estimations were performed with OLINDA/EXM 1.1 to be comparable with similar previous publications.
\end{abstract}

Results: The body regions receiving the highest absorbed doses were the pancreas, the urinary bladder wall, the small intestine and the kidneys (260, 69.8, 38.8 and $34.8 \mu \mathrm{Gy} / \mathrm{MBq}$ respectively). The ED considering a 30-min urinary voiding cycle was $17.6 \mu \mathrm{Sv} / \mathrm{MBq}$ in male patients. The increment of voiding time interval produced a significant increase of absorbed doses in bladder, prostate and testes, as well as an increase of ED. ED also increased if calculated with OLINDA/EXM 1.1. These results have been discussed in view of similar publications on bombesin analogues or on other commonly used theranostic peptides.

Conclusions: The pancreas is the most irradiated organ after the injection of ${ }^{68} \mathrm{Ga-NODAGA-MJ9}$, followed by the urinary bladder wall, the small intestine and the kidneys. ED is in the same range of other common ${ }^{68} \mathrm{Ga}$-labelled peptides. Differences with similarly published studies on bombesin analogues exist, and are mainly dependent on the methodology used for absorbed dose calculations.

Trial registration: Clinicaltrial.Gov identifier: NCT02111954, posted on 11/042014.

Keywords: Gastrin-releasing peptide receptor, Bombesin, Dosimetry, PET/CT, ${ }^{68}$ Ga-NODAGA-MJ9, OLINDA/EXM, Theranostics, Prostate cancer, Biochemical relapse, GRP antagonist

\footnotetext{
* Correspondence: silvano.gnesin@chuv.ch

${ }^{1}$ Institute of Radiation Physics, Lausanne University Hospital, Rue du

Grand-Pré 1, 1007 Lausanne, Switzerland

Full list of author information is available at the end of the article
} 


\section{Background}

The amphibian skin is a quasi-unlimited source of biologically active peptides, which have been the object of extensive pharmacological studies in the past decades [1]. Most of these peptides have their counterparts in vertebrate brain and gastrointestinal tract, an occurrence that has been named as the "braingut-skin triangle" [2]. A striking example of such triangle is the tetradecapeptide bombesin, which was isolated from the skin of the European amphibians Bombina bombina and Bombina variegata [3] several years before the identification and sequencing of its mammalian analogue, named gastrin-releasing peptide (GRP) [4]. Yet, the name GRP might not be fully appropriate, as bombesin and its human analogue exert a wide range of biological effects, including release of hormones from gastrointestinal and endocrine organs, contraction of smooth muscles, as well as central regulation of temperature and circadian rhythms [5]. In addition, GRP modulates the function of immune cells and, most importantly, it acts as an autocrine growth factor in several tumour types, including lung [6] and prostate cancer [7]. The mitotic activity of GRP in human tumours is largely mediated by the G-protein-coupled receptor BB2, also known as GRP-receptor (GRPR); interestingly, the interference with GRPR-mediated functions produces significant anti-mitotic effects $[5,8]$. It follows that the application of GRPR-targeting, radiolabelled bombesin analogues to the imaging and treatment of various neoplasms has raised considerable interest over the past 20 years [9].

Most of these research efforts have regarded prostate cancer, given the high density of GRPR since the early phase of neoplastic transformation [10]. The first radioactive bombesin analogues successfully used in prostate cancer patients were technetium-labelled GRPR agonists $[11,12]$. It was later realised that, despite poor internalisation, GRPR antagonists might be advantageous over GRPR agonists because of the lack of pharmacological effects and better tumour-to-background ratios, through a higher number of binding sites or a higher affinity [13]. The increasing clinical use of positron-emitting radionuclides for tumour imaging has prompted researchers to develop newer GRPR antagonists labelled with ${ }^{68} \mathrm{Ga},{ }^{18} \mathrm{~F}$, or ${ }^{64} \mathrm{Cu}$ [14], and it has been recently suggested that GRPR might complement prostate-specific membrane antigen (PSMA) for prostate cancer imaging [15].

The aim of the present study was to assess the human dosimetry of the GRPR antagonist ${ }^{68}$ Ga-NODAGA-4-amino-1-carboxymethyl-piperidine- - -Phe-Gln-Trp-Ala-Val-G ly-His-Sta-Leu- $\mathrm{NH}_{2}$ (NODAGA-MJ9) [16] in the first five patients with recurrent prostate cancer included in a dual-tracer positron emission tomography (PET) protocol.

\section{Materials and methods}

\section{Patients}

This dosimetry sub-study was designed to enrol the first five consecutive patients recruited in an imaging study comparing ${ }^{18}$ F-Fluorocholine and ${ }^{68} \mathrm{Ga}$-NODAGA-MJ9 as restaging modalities for prostate cancer in biochemical relapse (clinicaltrial.gov identifier NCT02111954, start date: April 2014). Aim of the dosimetry sub-study was to provide human absorbed dose estimations for ${ }^{68}$ Ga-NODAGA-MJ9, whereas dosimetry of ${ }^{18}$ F-Fluorocholine is already reported elsewhere [17]. Eligible patients presented a histologically confirmed prostate adenocarcinoma in biochemical relapse after a primary curative treatment (defined as prostate-specific antigen, PSA $>0.5 \mathrm{ng} / \mathrm{mL}$ after radical prostatectomy or with the nadir $+2 \mathrm{ng} / \mathrm{mL}$ definition after a primary radiotherapy [18]) for which ${ }^{18}$ F-Fluorocholine PET/CT was requested as restaging modality. Exclusion criteria were represented by the inability to provide written informed consent, age $<18$ years and ongoing androgen deprivation therapy. The Ethical Committee of Canton Vaud, Swissmedic and the Federal Office of Public Health (FOPH), authorised the study. Patients gave separate written informed consent to the clinical and the dosimetry protocols before radiopharmaceutical administration.

\section{Radiochemistry}

The NODAGA-MJ9 peptide was produced as a GMP product by CS Bio Co (Menlo Park, CA, USA). NODAGA-MJ9 was radiolabelled with the ${ }^{68} \mathrm{Ga}$ eluate of a ${ }^{68} \mathrm{Ge}$-generator IGG100 (Eckert \& Ziegler, Germany) using cassettes C4-GA68-FR on an automatic synthesis unit, Modular-Lab PharmTracer (Eckert \& Ziegler, Germany). ${ }^{68} \mathrm{Ga}$ was eluted with $0.1 \mathrm{~mol} / \mathrm{L} \mathrm{HCl}$. NODAGA-MJ9 $(20 \mu \mathrm{g})$ was radiolabelled with the high activity ${ }^{68} \mathrm{GaCl}_{3}$ fraction $(2 \mathrm{~mL}, 200-1300 \mathrm{MBq}$ ) by incubation for $20 \mathrm{~min}$ at room temperature. After $\mathrm{C}_{18}$-cartridge (Sep-Pak) pre-concentration, ${ }^{68} \mathrm{Ga}$-NODAGA-MJ9 was eluted with $50 \%$ aqueous ethanol $(0.8 \mathrm{~mL})$ through a $0.22 \mu \mathrm{m}$ sterile filter, and the cartridge and filter were rinsed with sterile $0.9 \% \mathrm{NaCl}$ solution $(7 \mathrm{~mL})$. High-pressure liquid chromatography (HPLC) analysis was performed at $220 \mathrm{~nm}$ on a $\mu$-Bondapak column (Waters $\mathrm{C} 18,3.9 \times 300 \mathrm{~mm}$ ) by gradient elution (solvent A: $0.01 \mathrm{M}$ TFA, solvent B: $\mathrm{CH}_{3} \mathrm{CN} / \mathrm{H}_{2} \mathrm{O}: 7 / 3+$ TFA, $8 / 2$ for $2 \mathrm{~min}$ then increase to $1 / 9 \mathrm{in} 8 \mathrm{~min}$ at $1.2 \mathrm{~mL} / \mathrm{min}$ ). Thin-layer chromatography (TLC) was performed using sodium acetate $1 \mathrm{M}$ in $\mathrm{MeOH} 1: 1$ on an activated iTLC-SG plate, with detection using a mini-Gita TLC scanner (Elysia-Raytest). Prior to release, all quality controls requested by the Swiss Federal authorities were met for a human injectable. 


\section{$\mathrm{PET} / \mathrm{CT}$ acquisition protocol}

Four whole-body PET scans (from top of the skull to mid femoral bone, $2 \mathrm{~min} /$ bed position) were acquired on a Discovery 690 time-of-flight (TOF) PET/CT (GE Healthcare, Waukesha, Wisconsin, USA) $15 \pm 2,45 \pm 2$, $70 \pm 5$ and $100 \pm 4$ min after the intravenous administration of $113 \pm 21 \mathrm{MBq}{ }^{68}$ Ga-NODAGA-MJ9. Patients were asked to void between scans (30-min voiding cycle). The list-mode acquisition integrating TOF information and point-spread-function recovery was reconstructed with a proprietary three-dimension ordered subset expectation maximisation (3D-OSEM) algorithm (GE-VPFXS, 3 iterations $\times 16$ subsets) including a FWHM $=5 \mathrm{~mm}$ Gaussian post-reconstruction filter [19]. All pertinent image corrections (normalisation, dead time, activity decay, random coincidence and attenuation and scatter corrections) were applied. The acquired field of view size was $70 \mathrm{~cm}$ reconstructed in a $256 \times 256$ image matrix. Reconstructed voxel size was $2.73 \times 2.73 \mathrm{~mm}$ in the transverse plane and $3.27 \mathrm{~mm}$ in the axial direction. Morphologic information was obtained from CT scan: $120 \mathrm{kVp}, 60 \mathrm{~mA}$ and pitch = 3; CT FOV diameter: $700 \mathrm{~mm}$; reconstructed image matrix size: $512 \times 512$; pixel spacing: $1.37 \times 1.37 \mathrm{~mm}$; and slice thickness: $3.75 \mathrm{~mm}$.

As previously described, quantitative accuracy for ${ }^{68} \mathrm{Ga}$ $\mathrm{PET} / \mathrm{CT}$ was assessed to be within $6 \%$ of the expected value [20].

\section{Organ segmentation}

Co-registered PET and CT data were loaded using PMOD (PMOD Technologies, Zurich, Switzerland). In PMOD, the CT matrix is used as reference for spatial resampling of PET data. Volumes of interest (VOI) were manually drawn slice by slice on the axial plane of the CT part of each PET/CT study using the polygonal segmentation tool of PMOD by two operators in consensus (SG and FC) for the following body regions: brain, thyroid, lungs, heart, liver, gallbladder, spleen, stomach, kidneys, adrenals, red marrow, intestines and whole body.

Pancreas and urinary bladder were manually segmented on the emission PET data.

CT-based segmentation of the bladder would have not taken into account possible changes of volume due to bladder filling during the PET/CT acquisition time. Manual segmentation of the pancreas based on the emission data was adopted to recover the actual organ activity by compensating for signal spill-out from the organ. No specific activity threshold was adopted for segmentation based on emission data. However, we estimated that the volume identified by our segmentation method corresponded to the volume that would result if a $5 \%$ of maximum activity threshold was adopted (data not shown).

\section{Absorbed dose estimations}

The total activity contained in each considered source organ was obtained by multiplication of the average activity concentration (expressed in $\mathrm{Bq} / \mathrm{mL}$ ) by the organ volume expressed in $\mathrm{mL}$. Measured activity in source organs at each time point was normalised to the administered patient activity. For all source organs but the gallbladder, a mono-exponential fit extended to infinite beyond the last measured data point was used to derive time-integrated activity coefficients (TIACs) by time-integration of source organ time-activity curves. The goodness of fit for each organ was expressed by the $R^{2}$ metric. In the gallbladder, radioactivity was still in the uptake phase at the last time point image. Therefore, between $t=0$ and $t=100 \mathrm{~min}$, the TIAC was obtained by trapezoidal integration using Matlab software (Release 2017a, The MathWorks, Inc., Natick, Massachusetts, USA), whereas a mono-exponential analytical integration to infinite was calculated after the last measure, assuming the ${ }^{68} \mathrm{Ga}$ physical decay. This approach can be considered largely conservative because it does not take into account the physiological voiding of the gallbladder content that would naturally occur within a few hours, and that would reduce the effective tracer half-life in the organ.

Bone marrow dosimetry was estimated by drawing three red marrow VOIs, in the head of humeral bone, in the heads of the femoral bone and in the lumbar vertebrae L3-L4, respectively. The total number of disintegrations in the bone marrow was calculated by multiplying the average number of disintegrations within these three VOIs by the red marrow mass of the ICRP- 89 adult male reference phantom [21]. To estimate the absorbed dose to the colon, the total number of disintegrations in this organ was partitioned to its components (right colon, left colon and rectum) proportionally to their respective masses of the ICRP-89 male reference phantom [21].

Organ TIACs were used in input to the OLINDA/ EXM $^{\circ} 2.0$ (HERMES Medical Solution AB, Stockholm, Sweden) code [22]. OLINDA/EXM 2.0 provided organabsorbed doses and effective dose (ED) per absorbed activity in $\mu \mathrm{Gy} / \mathrm{MBq}$ and $\mu \mathrm{Sv} / \mathrm{MBq}$, respectively, using the NURBS voxel-based phantoms [23] adjusted to the ICRP-89 organ masses [21] and ICRP103 tissue weighting factors $\left(\mathrm{w}_{\mathrm{T}}\right)$ [24]. Differences in organ absorbed doses estimated by varying the urinary voiding cycle in the range $0.5-3.5 \mathrm{~h}$ were assessed using two-sided unpaired Student's $t$ test.

By using the reference organ masses of OLINDA/EXM 2.0, we adopted a methodological approach typical of radioprotection, where the dosimetry of a reference adult subject is the major concern. Nevertheless, patient-specific dosimetry has also been performed and provided as Additional file 1: Table S1. 
In order to calculate the ED for the reference person, and in view of possible applications of GRPR targeting in breast cancer [11, 25-27], we simulated organ absorbed doses and ED for female patients. Accordingly, TIACs derived from our male patients were entered in OLINDA/EXM 2.0 and applied to the organ masses of the adult female phantom. The ED for the reference person was automatically computed by the OLINDA/EXM 2.0 code using both male and female equivalent organ doses according to the ICRP 103 methodology.

\section{Comparison with previous studies}

To facilitate the comparison with previous similar publications on dosimetry of bombesin analogues [28-34], we performed an additional absorbed dose estimation using our TIACs in input to OLINDA/EXM 1.1, which implements the Cristy \& Eckerman phantoms [35] and ICRP-60 tissue $\mathrm{w}_{\mathrm{T}}$ [36]. Absorbed dose calculations were performed using either a 1-h or a 3.5-h urinary voiding cycle, to allow direct comparison between our results and those of other authors using ${ }^{68} \mathrm{Ga}$-labelled bombesin analogues [30, 33, 34].

\section{Results}

\section{Patients}

Five prostate cancer patients (mean age 65, range 5672 years) with biochemical relapse after radical prostatectomy with or without postoperative radiotherapy were enrolled between April and May 2014. One patient had history of pancreatic adenocarcinoma treated with pancreaticoduodenectomy and adjuvant radiochemotherapy, in clinical remission at the time of inclusion. Two patients had undergone cholecystectomy due to gallstones. Table 1 summarises patients' characteristics and the main ${ }^{68}$ Ga-NODAGA-MJ9 PET/CT findings. Preliminary results of the comparison between ${ }^{18} \mathrm{~F}$-Fluorocholine and ${ }^{68}$ Ga-NODAGA-MJ9 in the relapse setting were previously reported in an abstract form [37]. Definitive results of the main clinical study are not yet available and will be reported elsewhere.

\section{Radiochemistry}

The ${ }^{68}$ Ga-NODAGA-MJ9 radiochemical purity was $\geq 95 \%$ by iTLC and $<5 \%$ free Gallium. By HPLC, the radiochemical purity was $\geq 95 \%{ }^{68}$ Ga-NODAGA-MJ9 with a retention time of $9.0 \mathrm{~min}$. There was less than $0.001 \%{ }^{68} \mathrm{Ge}$ radionucleidic impurity. The synthesis time of ${ }^{68} \mathrm{Ga}-\mathrm{NO}$ DAGA-MJ9 was $33 \mathrm{~min}$ overall. The specific activity at end of synthesis (EOS) was $6-40 \mathrm{GBq} / \mathrm{mg}$, with a peptide weight of $20 \mu \mathrm{g}$. The volumetric activity EOS was $15-103 \mathrm{MBq} / \mathrm{mL}$.

\section{Imaging}

All injections were well-tolerated. No immediate symptoms or modification of vital signs were observed. Typical biodistribution of ${ }^{68} \mathrm{Ga}$-NODAGA-MJ9 is shown in Fig. 1. The radiopharmaceutical is excreted via both urinary and hepato-biliary routes. Urinary bladder uptake is seen as early as $15 \mathrm{~min}$ after injection. No radiopharmaceutical retention is observed in the renal cortex, while the gallbladder is still in the biological uptake phase at the last imaging time point, 100 min after injection. A high and homogeneous pancreatic tracer uptake is seen.

\section{Absorbed dose estimations}

Time-activity curves for relevant abdominal organs are shown in Fig. 2. Organ time-activity curves corrected for ${ }^{68} \mathrm{Ga}$ physical decay are shown in Fig. 3. Measured TIACs, organ absorbed doses and ED of the patients enrolled, as well as the extrapolated values to female and reference person, are reported in Table 2.

The organ receiving the highest absorbed dose was the pancreas $(260 \mu \mathrm{Gy} / \mathrm{MBq})$, followed by the urinary bladder wall, the small intestine and the kidneys $(69.8,38.8$ and $34.8 \mu \mathrm{Gy} / \mathrm{MBq}$ respectively).

Using a 30-min urinary voiding cycle, we obtained an $\mathrm{ED}$ of $17.6 \mu \mathrm{Sv} / \mathrm{MBq}$ in our male patients. The extrapolation to 1-h voiding cycle resulted in EDs of 18.8 and $23.0 \mu \mathrm{Sv} / \mathrm{MBq}$ for male and female, respectively. The corresponding ED for the reference person was $21.7 \mu \mathrm{Sv} / \mathrm{MBq}$.

The increment of voiding time interval produced a significant increase of absorbed doses in the following

Table 1 Patient characteristics

\begin{tabular}{lllllll}
\hline Patient & Age (years) & BMl $\left(\mathrm{kg} / \mathrm{m}^{2}\right)$ & Gleason score & PSA $(\mathrm{ng} / \mathrm{ml})$ & PSA doubling time (months) & ${ }^{68} \mathrm{Ga}-\mathrm{MJ9}$ PET/CT findings \\
\hline 1 & 62 & 31.4 & 9 & 8.5 & 2 & Lymph nodes + bone metastases \\
$2^{\text {a }}$ & 68 & 22.1 & 7 & 2.3 & 1 & Bone metastases \\
$3^{\text {b }}$ & 67 & 27.5 & 6 & 3.4 & 18 & Bone metastases \\
$4^{\text {b }}$ & 72 & 24.9 & 9 & 7.7 & 4.4 & Lymph-nodal metastases \\
5 & 56 & 24.3 & 8 & 7.3 & 12 & Local relapse \\
\hline
\end{tabular}

${ }^{a}$ History of pancreatic carcinoma treated with pancreaticoduodenectomy, and adjuvant chemo- and radiotherapy

${ }^{b}$ History of gallstones treated with cholecystectomy 

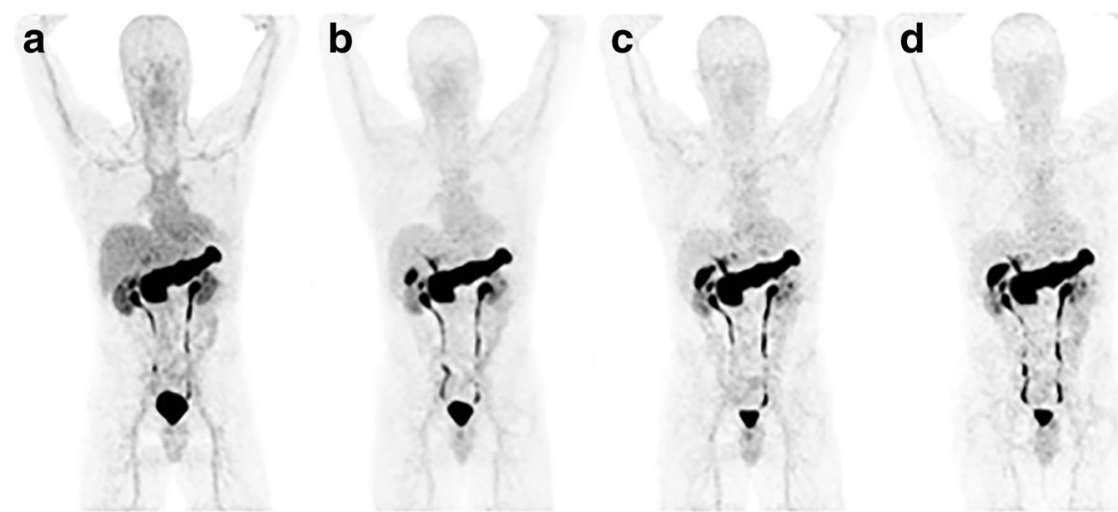

Fig. 1 Maximum intensity projections acquired 10, 45, 70 and 100 min after ${ }^{68} \mathrm{Ga-NODAGA-MJ9}$ injection (a-d, respectively) in a 56-year-old patient with biochemical relapse of prostate cancer (patient \#5). The typical ${ }^{68} \mathrm{Ga}-\mathrm{NODAGA-MJ9}$ biodistribution is observed, including visualisation of the urinary system, as well as fast and prominent uptake by the pancreas and the biliary tract

organs: urinary bladder wall $(+60 \%$ for 1 -h vs. $0.5-\mathrm{h}$ voiding cycle, $p=0.001$, and $+186 \%$ for 3.5 -h vs. 0.5 -h voiding cycle, $p<0.0001)$, prostate $(+9 \%$ for 1 -h vs. 0.5 -hvoiding cycle, $p=0.034$, and $+29 \%$ for 3.5 -h vs. 0.5 -h voiding cycle, $p<0.0001)$ and testes $(+2 \%$ for 1 -h vs. 0.5 -h voiding cycle, $p=0.48$, and $+8.5 \%$ for 3.5 -h vs. 0.5 -h voiding cycle, $p=0.039)$. ED increased as well with the voiding time interval $(+7 \%$ for 1 -h vs. 0.5 -h voiding cycle, $p=0.032$, and $+33 \%$ for 3.5 -h vs. 0.5 -h voiding cycle, $p<0.0001$ ).

\section{Comparison with previous studies}

Results of our absorbed dose estimations performed with OLINDA/EXM 1.1 assuming 1-h and 3.5-h voiding cycles are reported as Additional file 2: Table S2.

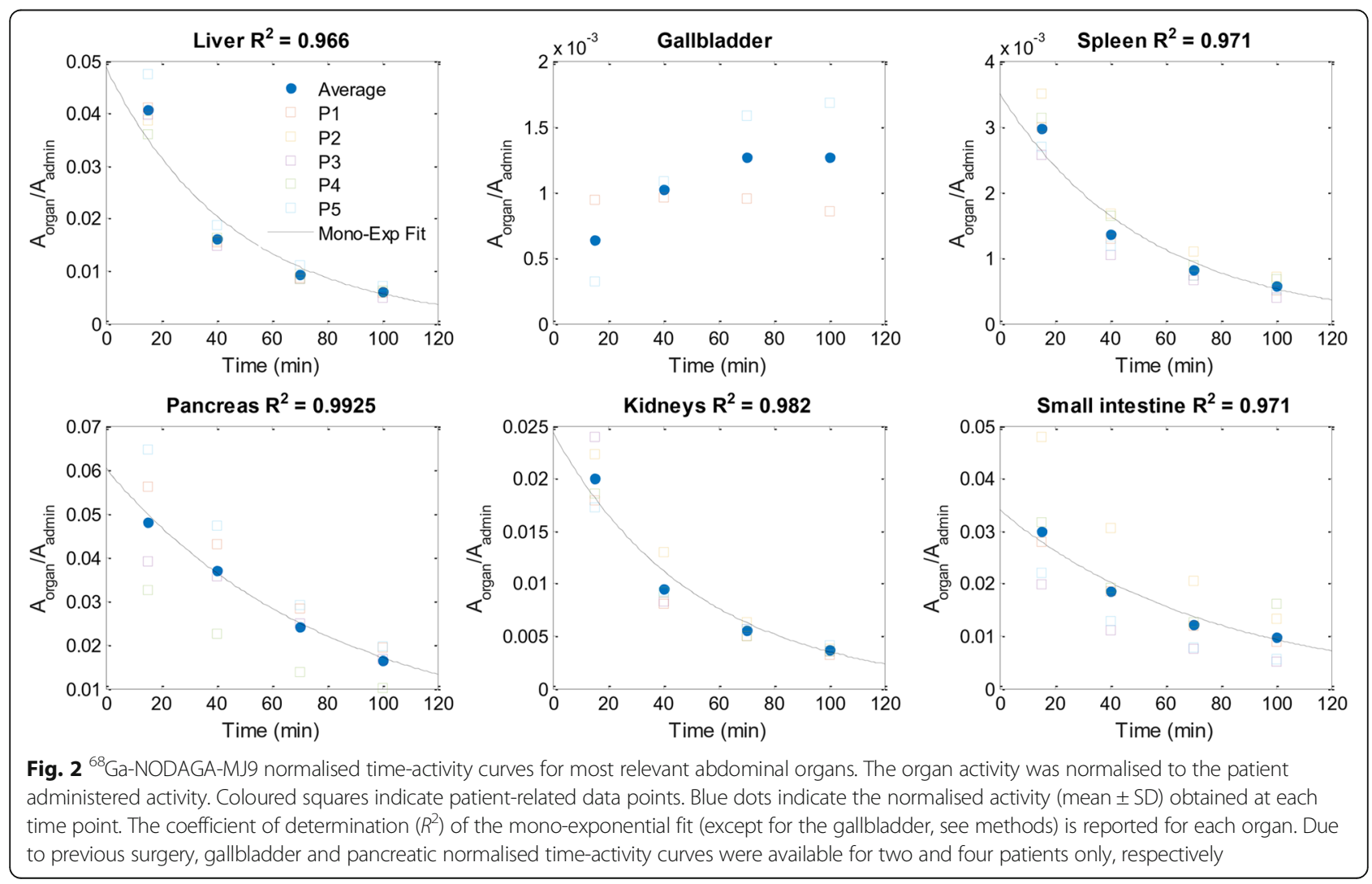




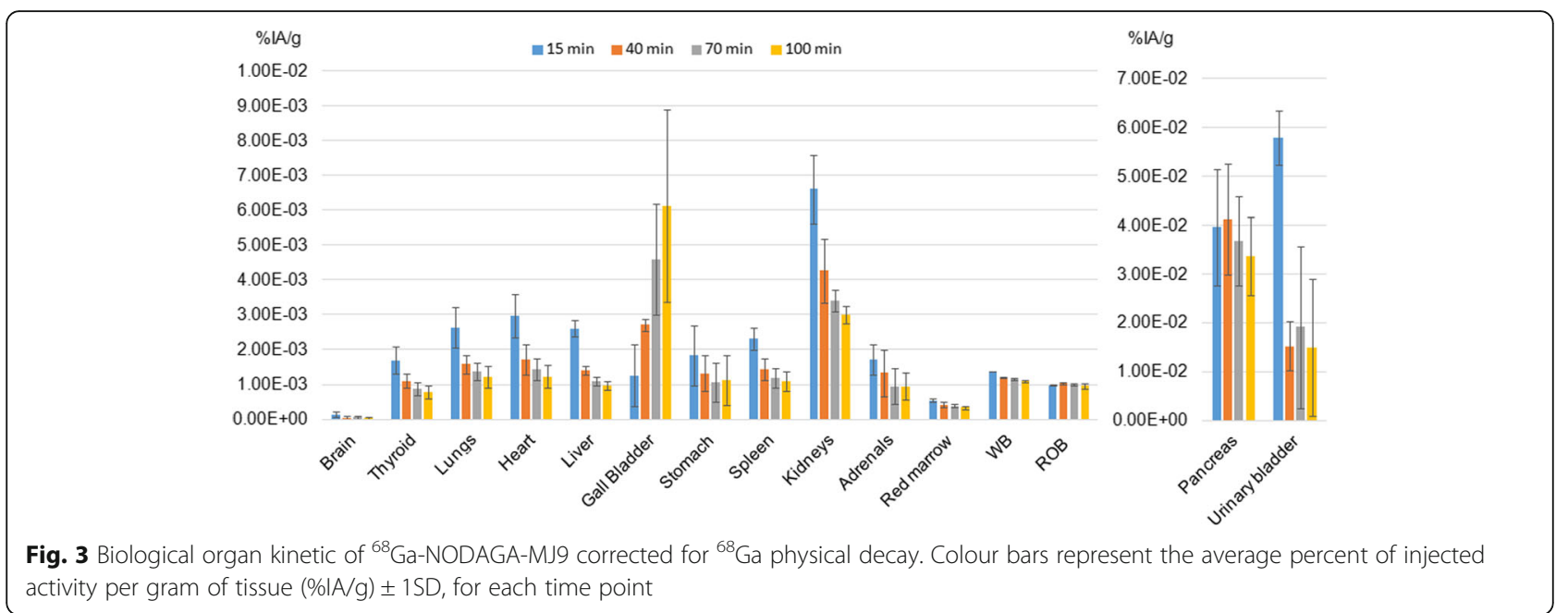

Previously published papers on dosimetry of bombesin analogues were hardly comparable as they used various radionuclides, including ${ }^{99 \mathrm{~m}} \mathrm{Tc}[28,29],{ }^{64} \mathrm{Cu}[31],{ }^{18} \mathrm{~F}$ [32] or ${ }^{68} \mathrm{Ga}[30,33,34]$, different tracer molecules, different study subjects and dosimetry methodologies. Organ-absorbed dose estimations were heterogeneous even among studies using ${ }^{68} \mathrm{Ga}$-labelled bombesin analogues [30, 33, 34]. Absorbed doses of single organs varied greatly between the present study and that of Zhang et al. on the ${ }^{68} \mathrm{Ga}$-labelled GRPR agonist NOTAAca-BBN [33]. As an example, based on the results obtained with OLINDA/EXM 1.1 (Additional file 2: Table S2), the absorbed dose to the gallbladder was three times higher, whereas the absorbed dose to the pancreas was 368 times lower in [33] than in the present study. In turn, our organ absorbed dose estimations were, on average, about 70 times higher than those of Zhang et al. [33] (full data not shown). Nevertheless, EDs for reference person were similar: $2.76 \mathrm{E}-02$ vs $3.1 \mathrm{E}-02 \mathrm{mSv} / \mathrm{MBq}$ in [33] and the present study, respectively. This can be attributed to the fact that organs with the highest $\mathrm{w}_{\mathrm{T}}$, such as the gonads $\left(w_{T}=0.2\right)$, received nearly similar doses in both studies.

Although obtained on healthy individuals, the organ-absorbed dose estimations found by Roivainen et al. [30] and by a further publication of Zhang et al. [34] were in the same order of magnitude as ours. These studies were conducted using the ${ }^{68} \mathrm{Ga}$-labelled antagonists DOTA-BAY 86-7548 [30] and NOTA-RM26 [34], respectively. A dosimetry comparison with the present study for most relevant parenchymal organs and bone marrow is given in Fig. 4. In our study, the estimated ED for male was lower than in [30] and [34] (2.79E-02 vs $3.8 \mathrm{E}-02$ vs $6.57 \mathrm{E}-02 \mathrm{mSv} / \mathrm{MBq}$ in the present study, in [30] and in [34], respectively, 1-h voiding cycle).

\section{Discussion}

GRPR, also known as BB2, is receiving great attention as a theranostic target. The most exploited field of application of GRPR-targeting peptides is prostate cancer, although bombesin analogues might be relevant for other highly prevalent tumours [9]. In the work-up of prostate cancer, radiolabelled bombesin analogues might complement other diagnostic probes, such as ${ }^{18} \mathrm{~F}$-choline, ${ }^{11} \mathrm{C}$-acetate or ${ }^{68}$ Ga-PSMA, or even compete with them $[15,38]$. As regards therapeutic applications, radiolabelled bombesin analogues might be advantageous because of the lack of significant uptake by the lacrimal or salivary glands, which is of serious concern in radionuclide therapy with PSMA [39].

Among several GRPR-targeting imaging probes, the statin-based antagonist ${ }^{68}$ Ga-NODAGA-MJ9 has shown favourable binding properties and has the advantage of being labelled with high efficiency at room temperature [16]. In the present study, we have assessed the dosimetry of ${ }^{68} \mathrm{Ga}$-NODAGA-MJ9 in five patients with relapsing prostate adenocarcinoma. We discuss our results below, with a particular focus on the comparison with similar studies on bombesin analogues and on other theragnostic peptides.

The single organ receiving the highest absorbed dose was the pancreas $(260 \mu \mathrm{Gy} / \mathrm{MBq})$. This is in agreement with the notion that pancreas is probably the organ expressing the highest amount of GRPR [5], and in line with previous studies on biodistribution and dosimetry of radiolabelled bombesin analogues in mice [40] and in humans [30, 31, 34].

Although relatively high, such absorbed doses are unlikely to produce clinically relevant pancreatic toxicities in case of therapeutic administrations of radiolabelled bombesin analogues. In fact, we estimated that the absorbed dose to the pancreas would be 1.85 Gy for the administration of a 
Table 2 Residence times, organ-absorbed doses and ED according to OLINDA/EXM 2.0 for 30-min and 1-h urinary voiding cycles in men. Extrapolated organ-absorbed doses in female and reference person are reported for 1-h urinary voiding cycle only

\begin{tabular}{|c|c|c|c|c|c|c|c|c|}
\hline \multirow[t]{5}{*}{ Target organ } & \multicolumn{8}{|c|}{ Patient cohort ( $n=5$ male) } \\
\hline & \multirow{2}{*}{\multicolumn{2}{|c|}{ Residence time (h) }} & \multirow{2}{*}{\multicolumn{2}{|c|}{$\frac{\text { Male }}{0.5 \mathrm{~h} \text { voiding }}$}} & \multicolumn{2}{|l|}{ Male } & \multirow{3}{*}{$\begin{array}{l}\text { Female } \\
1 \mathrm{~h} \text { voiding } \\
\text { Dose }\end{array}$} & \multirow{3}{*}{$\begin{array}{l}\text { Reference } \\
1 \mathrm{~h} \text { voiding } \\
\text { Dose }\end{array}$} \\
\hline & & & & & \multicolumn{2}{|c|}{$1 \mathrm{~h}$ voiding } & & \\
\hline & \multirow[t]{2}{*}{ Mean } & \multirow[t]{2}{*}{ SD } & Dose & SD & Dose & SD & & \\
\hline & & & $\mathrm{mGy} / \mathrm{MBq}$ & & $\mathrm{mGy} / \mathrm{MBq}$ & & $\mathrm{mGy} / \mathrm{MBq}$ & mGy/MBq \\
\hline Adrenals & $2.48 \mathrm{E}-04$ & 8.49E-05 & $1.48 \mathrm{E}-02$ & $2.22 \mathrm{E}-03$ & $1.46 \mathrm{E}-02$ & $2.13 \mathrm{E}-03$ & $1.57 \mathrm{E}-02$ & $1.52 \mathrm{E}-02$ \\
\hline Brain & $1.53 \mathrm{E}-03$ & $1.05 \mathrm{E}-03$ & $1.71 \mathrm{E}-03$ & $3.12 \mathrm{E}-04$ & $1.71 \mathrm{E}-03$ & $3.20 \mathrm{E}-04$ & $3.62 \mathrm{E}-03$ & $2.68 \mathrm{E}-03$ \\
\hline Breast & - & - & - & - & - & - & 1.06E-02 & 1.06E-02 \\
\hline Esophagus & - & - & $1.06 \mathrm{E}-02$ & 5.47E-04 & $1.06 \mathrm{E}-02$ & $5.22 \mathrm{E}-04$ & $1.25 \mathrm{E}-02$ & $1.16 \mathrm{E}-02$ \\
\hline Eyes & - & - & 8.39E-03 & 4.70E-04 & 8.39E-03 & 4.56E-04 & $1.02 \mathrm{E}-02$ & $9.32 \mathrm{E}-03$ \\
\hline Gallbladder wall ${ }^{a}$ & 3.60E-03 & $1.27 \mathrm{E}-03$ & 2.69E-02 & 5.59E-03 & 2.69E-02 & $5.66 \mathrm{E}-03$ & 2.19E-02 & $1.99 \mathrm{E}-02$ \\
\hline Left colon & $6.73 \mathrm{E}-03$ & 3.33E-03 & $3.37 E-02$ & 9.04E-03 & $3.38 \mathrm{E}-02$ & $9.01 \mathrm{E}-03$ & $3.27 \mathrm{E}-02$ & $3.08 \mathrm{E}-02$ \\
\hline Small Intestine ${ }^{a}$ & 4.01E-02 & $1.71 \mathrm{E}-02$ & $3.88 \mathrm{E}-02$ & $1.05 \mathrm{E}-02$ & $3.90 \mathrm{E}-02$ & 1.04E-02 & 4.04E-02 & $3.76 \mathrm{E}-02$ \\
\hline Stomach wall ${ }^{a}$ & 4.79E-03 & $2.45 \mathrm{E}-03$ & $1.92 \mathrm{E}-02$ & $1.53 \mathrm{E}-03$ & $1.92 \mathrm{E}-02$ & $1.53 \mathrm{E}-03$ & $2.00 \mathrm{E}-02$ & $1.91 \mathrm{E}-02$ \\
\hline Right colon & 1.35E-02 & $6.66 \mathrm{E}-03$ & $3.21 \mathrm{E}-02$ & $1.01 \mathrm{E}-02$ & $3.22 \mathrm{E}-02$ & $1.01 \mathrm{E}-02$ & $3.28 \mathrm{E}-02$ & $3.00 \mathrm{E}-02$ \\
\hline Rectum & $6.73 \mathrm{E}-03$ & 3.33E-03 & $3.18 \mathrm{E}-02$ & $1.02 \mathrm{E}-02$ & $3.25 \mathrm{E}-02$ & $9.84 \mathrm{E}-03$ & $3.58 \mathrm{E}-02$ & 3.17E-02 \\
\hline Heart wall ${ }^{a}$ & $2.16 \mathrm{E}-02$ & $5.45 \mathrm{E}-03$ & 2.13E-02 & $2.26 \mathrm{E}-03$ & $2.13 \mathrm{E}-02$ & $2.26 \mathrm{E}-03$ & 2.70E-02 & $2.42 \mathrm{E}-02$ \\
\hline Kidneys & $2.14 \mathrm{E}-02$ & $2.23 \mathrm{E}-03$ & $3.48 \mathrm{E}-02$ & 3.04E-03 & $3.48 \mathrm{E}-02$ & 3.03E-03 & $3.31 \mathrm{E}-02$ & $3.40 \mathrm{E}-02$ \\
\hline Liver & $3.79 \mathrm{E}-02$ & 2.93E-03 & $1.41 \mathrm{E}-02$ & $8.41 \mathrm{E}-04$ & $1.41 \mathrm{E}-02$ & $8.41 \mathrm{E}-04$ & $1.85 \mathrm{E}-02$ & $1.63 \mathrm{E}-02$ \\
\hline Lungs & 2.88E-02 & $5.98 \mathrm{E}-03$ & 1.34E-02 & $1.95 \mathrm{E}-03$ & $1.34 \mathrm{E}-02$ & $1.95 \mathrm{E}-03$ & 1.66E-02 & $1.50 \mathrm{E}-02$ \\
\hline Ovaries & - & - & - & - & - & - & 1.50E-02 & 1.49E-02 \\
\hline Pancreas & $8.13 \mathrm{E}-02$ & $1.95 \mathrm{E}-02$ & $2.60 \mathrm{E}-01$ & $6.14 \mathrm{E}-02$ & $2.60 \mathrm{E}-01$ & $6.14 \mathrm{E}-02$ & 2.43E-01 & - \\
\hline Prostate & - & - & $1.22 \mathrm{E}-02$ & $5.52 \mathrm{E}-04$ & 1.33E-02 & 7.91E-04 & - & 1.33E-02 \\
\hline Salivary glands & - & - & $9.12 \mathrm{E}-03$ & $5.06 \mathrm{E}-04$ & $9.12 \mathrm{E}-03$ & 4.93E-04 & 1.07E-02 & 9.93E-03 \\
\hline Red marrow & 7.10E-03 & 8.59E-04 & $9.38 \mathrm{E}-03$ & 4.18E-04 & 9.49E-03 & 4.06E-04 & $1.17 \mathrm{E}-02$ & 1.17E-02 \\
\hline Osteogenic cells & - & - & $6.83 \mathrm{E}-03$ & 3.23E-04 & $6.89 \mathrm{E}-03$ & $3.21 \mathrm{E}-04$ & 7.71E-03 & 7.87E-03 \\
\hline Spleen & 3.16E-03 & $6.73 \mathrm{E}-04$ & 1.37E-02 & $1.58 \mathrm{E}-03$ & 1.37E-02 & $1.58 \mathrm{E}-03$ & 1.55E-02 & $1.46 \mathrm{E}-02$ \\
\hline Testes & - & - & $9.56 \mathrm{E}-03$ & $5.28 \mathrm{E}-04$ & $9.82 \mathrm{E}-03$ & 5.59E-04 & - & $9.82 \mathrm{E}-03$ \\
\hline Thymus & - & - & $1.02 \mathrm{E}-02$ & $3.99 \mathrm{E}-04$ & $1.02 \mathrm{E}-02$ & $3.60 \mathrm{E}-04$ & $1.29 \mathrm{E}-02$ & $1.15 \mathrm{E}-02$ \\
\hline Thyroid & $3.20 \mathrm{E}-04$ & 5.00E-05 & $9.32 \mathrm{E}-03$ & 8.30E-04 & $9.15 \mathrm{E}-03$ & $8.21 \mathrm{E}-04$ & 1.05E-02 & $9.85 \mathrm{E}-03$ \\
\hline Urinary bladder wall ${ }^{a}$ & $8.77 \mathrm{E}-02$ & 1.69E-02 & $6.98 \mathrm{E}-02$ & $1.26 \mathrm{E}-02$ & $1.12 \mathrm{E}-01$ & 1.97E-02 & 1.39E-01 & $1.25 \mathrm{E}-01$ \\
\hline Uterus & - & - & - & - & - & - & $1.78 \mathrm{E}-02$ & $1.76 \mathrm{E}-02$ \\
\hline Total body & - & - & $1.14 \mathrm{E}-02$ & 5.24E-04 & 1.17E-02 & 5.87E-04 & $1.43 \mathrm{E}-02$ & $1.30 \mathrm{E}-02$ \\
\hline ED ICRP 103 (mSv/MBq) & - & - & $1.76 \mathrm{E}-02$ & 1.07E-03 & $1.88 \mathrm{E}-02$ & $1.16 \mathrm{E}-03$ & $2.30 \mathrm{E}-02$ & 2.17E-02 \\
\hline
\end{tabular}

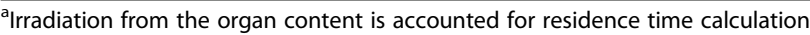

theoretical ${ }^{177} \mathrm{Lu}$-labelled MJ9 compound given at a standard therapeutic activity of 7.4 GBq (Additional file 3: Table S3). This theoretical estimation, although artificially obtained from our measured ${ }^{68} \mathrm{Ga}$-based organ biokinetics, can be considered largely safe as no relevant pancreatic toxicity has been observed for absorbed doses that are at least one order of magnitude higher in external beam radiotherapy which, although not optimal, is presently our only term of comparison [41, 42].

Of note, two previous PET-based dosimetry studies reported substantially inferior radiation absorbed doses to the pancreas after the injection of ${ }^{18} \mathrm{~F}$-BAY 864367 [32] and ${ }^{68} \mathrm{Ga}-\mathrm{NOTA}$-Aca-BBN [33] (14.36 $\mu \mathrm{Gy} / \mathrm{MBq}$ and $1.05 \mu \mathrm{Gy} / \mathrm{MBq}$, respectively). These results are questionable, as the pancreas clearly shows a prominent uptake on the PET images featured by these publications $[32,33]$. In the striking case of [33], the radiation-absorbed dose reported for the pancreas was even lower than that reported for the muscle $(1.39 \mu \mathrm{Gy} / \mathrm{MBq})$. These important discrepancies are unlikely justified by different tracer kinetics; rather they are probably due to different methodologies used for dose calculations. This highlights the need 


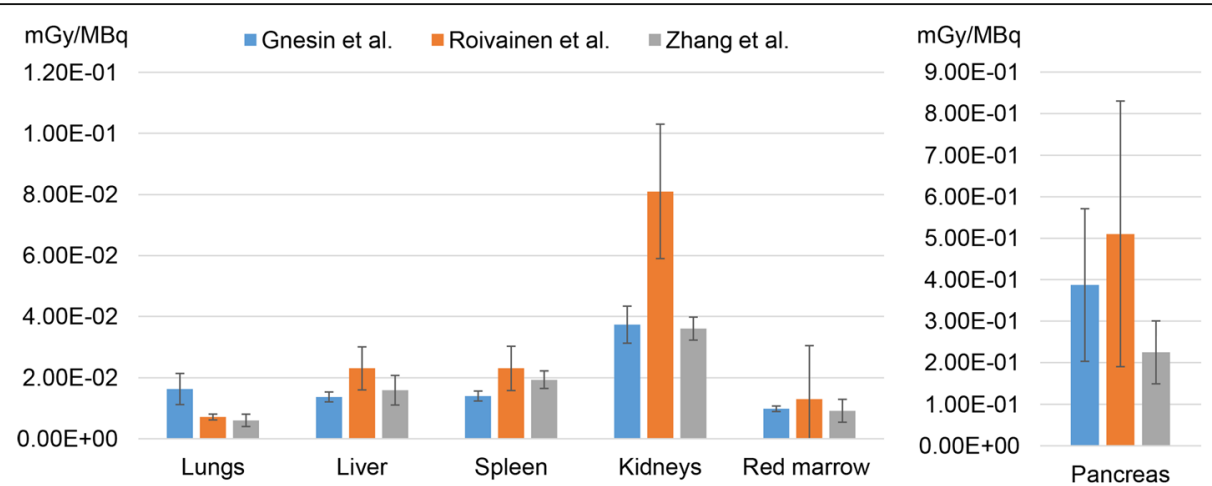

Fig. 4 Dosimetry comparison between our study and those of Roivainen et al. [30] and Zhang et al. [34] based on OLINDA/EXM 1.0. The absorbed dose estimations reported in this figure are based on either a 3.5-h urinary voiding cycle (our study and that of Roivainen et al. [30]) or on a 1-h voiding cycle (Zhang et al. [34]). It should be noted that, for the organs reported, variations of urinary voiding cycle do not produce significant changes of absorbed dose estimations. Error bars represent $\pm 2 \mathrm{SD}$

for a standardisation of methodology and data reporting in clinical dosimetry procedures.

The absorbed dose to the kidneys resulted to be $34.8 \mu \mathrm{Gy} / \mathrm{MBq}$ for $\left.{ }^{68} \mathrm{Ga}-\mathrm{NODAGA}-\mathrm{M}\right) 9$, which is lower than that estimated for other ${ }^{68} \mathrm{Ga}$-labelled peptides, such as PSMA or somatostatin analogues [43-47]. Overall, these studies showed absorbed doses to the kidneys ranging from 89 to $262 \mu \mathrm{Gy} / \mathrm{MBq}$ [43-47].

In the present study, by assuming a urinary voiding interval of $1 \mathrm{~h}$, we calculated an ED of $18.8 \mu \mathrm{Sv} / \mathrm{MBq}$ in men, which would correspond to $2.8 \mathrm{mSv}$ after a tracer injection of $150 \mathrm{MBq}{ }^{68} \mathrm{Ga}-$ NODAGA-MJ9. This estimated ED falls within the range 16.7-25.7 $\mu$ Sv/MBq reported for other ${ }^{68} \mathrm{Ga}$-labelled peptides [43-47]. However, differently from previous studies, our absorbed dose calculations were based on OLINDA/EXM 2.0. If the absorbed dose estimation is made with OLINDA/ EXM 1.1, the ED in male increases up to $27.9 \mu \mathrm{Sv} / \mathrm{MBq}$ for ${ }^{68} \mathrm{Ga}$-NODAGA-MJ9. The lower ED estimated with OLINDA/EXM 2.0 can be explained, in first instance, by a lower tissue $\mathrm{w}_{\mathrm{T}}$ attributed to the most irradiated organ, that is the pancreas in our case $\left(\mathrm{w}_{\mathrm{T}}\right.$ pancreas $=0.025$ vs. 0.0092 in OLINDA/EXM 1.1 and OLINDA/EXM 2.0, respectively) [24]. Secondarily, the phantoms implemented in OLINDA/EXM 1.1 and OLINDA/EXM 2.0 consider two different organ masses for the pancreas (94.3 g vs. $140 \mathrm{~g}$ in OLINDA/EXM 1.1 and OLINDA/EXM 2.0 respectively), which has an additional impact on the calculation of the ED. Consequently, in our specific case of ${ }^{68}$ Ga-NODAGA-MJ9, the equivalent dose to the pancreas accounts for $35 \%$ of the ED in OLINDA/EXM 1.1, whereas it accounts for only $13 \%$ of the ED in OLINDA/EXM 2.0.

As discussed by some authors [43, 48], in OLINDA/ EXM 2.0, EDs would be lower compared to OLINDA/ EXM 1.1 for both ${ }^{68}$ Ga-labelled PSMAs and somatostatin analogues, as well. Therefore, whatever version of OLINDA/EXM is used, ED is slightly higher for ${ }^{68} \mathrm{Ga}$-NODAGA-MJ9 than for ${ }^{68} \mathrm{Ga}$-labelled PSMAs or somatostatin analogues.

This study has inherent limitations due to the small number of patients. Moreover, by chance, one patient had history of pancreatic carcinoma treated with pancreaticoduodenectomy, and two additional patients had their gallbladder surgically removed for gallstones. This has further reduced the number of our observations.

In addition, dosimetry data regarding prostate gland have probably little clinical significance in the context of our study. In fact, we enrolled only patients who had their prostate surgically removed, so that absorbed doses to the prostate have been estimated by the software considering only the contribution of neighbouring organs as sources of radiation. Analogously, our extrapolation to female dosimetry should be interpreted with caution, especially concerning the estimated absorbed dose to breast and reproductive organs. Nevertheless, the dosimetry calculation for female subject is required in order to calculate the ED which, according to the ICRP103 methodology [24], is based on both male and female organ equivalent dose ponderation.

\section{Conclusions}

We have performed the first human dosimetry of ${ }^{68} \mathrm{Ga}$-NODAGA-MJ9. Our data shows the pancreas to be the most irradiated organ in ${ }^{68} \mathrm{Ga}$-NODAGA-MJ9 diagnostic procedures, followed by the urinary bladder wall, the small intestine, and the kidneys. ED is in the same range of other common ${ }^{68} \mathrm{Ga}$-labelled peptides. The differences of dosimetry results between the present study and other previous works on radiolabelled bombesin analogues mainly depend on the methodology used for absorbed dose calculations. 


\section{Additional files}

Additional file 1: Table S1. Patient-specific dosimetry for the five male subjects included in the study (1-h urinary voiding cycle). (DOCX $25 \mathrm{~kb}$ )

Additional file 2: Table S2. Extrapolated organ absorbed doses and ED according to OLINDA/EXM 1.1 for 1 -h and $3.5 \mathrm{~h}$ urinary voiding cycles in male, female and the reference person. (DOCX $19 \mathrm{~kb}$ )

Additional file 3: Table 3. Extrapolated absorbed doses to the pancreas per administered GBq of a theoretical ${ }^{177}$ Lu-MJ9 analogue. (DOCX 20 kb)

\section{Acknowledgments}

We thank Ms. Catherine Servis, PhD from the Department of Biochemistry, University of Lausanne for advice and collaboration with obtaining the GMP peptide synthesis. We are indebted to Franz Buchegger, MD (retired from Department of Nuclear Medicine and Molecular Imaging, Lausanne University Hospital, Switzerland) for initiating this project in collaboration with Rosalba Mansi, Ph.D. (Division of Radiopharmaceutical Chemistry, Clinic of Radiology and Nuclear Medicine, University Hospital Basel, Basel, Switzerland) and Prof. Helmut R. Maecke (Department of Nuclear Medicine, University Hospital Freiburg, Freiburg, Germany) who initially developed this radiopharmaceutical. We acknowledge the help of Marek Kosinski, Ph.D. (retired from Department of Nuclear Medicine and Molecular Imaging, Lausanne University Hospital, Switzerland) for performing the ${ }^{68} \mathrm{Ga}-$ NODAGA-MJ9 syntheses. Finally, we would like to express our sincere gratitude to Thibaut Denoël, Ph.D., for the enlightening discussions we had and for his in-depth revision of the article.

\section{Funding}

Financial support was obtained through a generous gift from Fundación Privada Cellex, Barcelona, Spain and the Department of Nuclear Medicine and Molecular Imaging of the Lausanne University Hospital, Lausanne, Switzerland.

\section{Availability of data and materials}

The datasets used and/or analysed during the current study are available from the corresponding author on reasonable request.

\section{Authors' contributions}

SG, SB, RM, TZ, and JOP are responsible for the design of the study. PM and AVDG are responsible for the data acquisition. PM, RM, VG, and TZ are responsible for patients' selection and follow up. SG, FC, SB, VG, and JOP are responsible for the data analysis and critical evaluation of the results. SG, AVDG, and FC are responsible for the manuscript writing. SG, FC, PM, AVDG, $\mathrm{SB}, \mathrm{RM}, \mathrm{VG}, \mathrm{TZ}$, and JOP are responsible for the approval of the final form.

\section{Ethics approval and consent to participate}

All procedures performed in the study were in accordance with the standards of the institutional ethical committee and with the 1964 Helsinki Declaration and its later amendments or comparable ethical standards. The study was authorised by the Ethical Committee of Canton Vaud, Swissmedic and the Federal Office of Public Health (FOPH) (clinicaltrial.gov identifier NCT02111954, start date: April 2014).

Informed consent for the dosimetric procedures and for publication of the results was obtained from all individual participants included in the study. This article does not contain any studies with animals performed by any of the authors.

\section{Consent for publication}

All patients gave written informed consent for publication of their individual data, if adequately anonymised.

\section{Competing interests}

The authors declare that they have no competing interests.

\section{Publisher's Note}

Springer Nature remains neutral with regard to jurisdictional claims in published maps and institutional affiliations.

\section{Author details}

'Institute of Radiation Physics, Lausanne University Hospital, Rue du Grand-Pré 1, 1007 Lausanne, Switzerland. ²Department of Nuclear Medicine and Molecular Imaging, Lausanne University Hospital, Lausanne, Switzerland. ${ }^{3}$ Department of Radiation Oncology, University Hospital of Geneva and Geneva University, Geneva, Switzerland. ${ }^{4}$ Division of Nuclear Medicine and Molecular Imaging, University Hospital of Geneva and Geneva University, Geneva, Switzerland

Received: 20 September 2018 Accepted: 26 November 2018

Published online: 12 December 2018

\section{References}

1. Bevins CL, Zasloff M. Peptides from frog skin. Annu Rev Biochem. 1990;59: 395-414.

2. Erspamer V, Melchiorri P, Broccardo M, Erspamer GF, Falaschi $P$, Improota $G$, et al. The brain-gut-skin triangle: new peptides. Peptides. 1981;2(Suppl 2):7-16.

3. Anastasi A, Erspamer V, Bucci M. Isolation and structure of bombesin and alytesin, 2 analogous active peptides from the skin of the European amphibians Bombina and Alytes. Experientia. 1971;27(2):166-7.

4. McDonald TJ, Jornvall H, Nilsson G, Vagne M, Ghatei M, Bloom SR, et al. Characterization of a gastrin releasing peptide from porcine non-antral gastric tissue. Biochem Biophys Res Commun. 1979;90(1):227-33.

5. Jensen RT, Battey JF, Spindel ER, Benya RV. International Union of Pharmacology. LXVIII. Mammalian bombesin receptors: nomenclature, distribution, pharmacology, signaling, and functions in normal and disease states. Pharmacol Rev. 2008:60(1):1-42.

6. Cuttitta F, Carney DN, Mulshine J, Moody TW, Fedorko J, Fischler A, et al. Bombesin-like peptides can function as autocrine growth factors in human small-cell lung cancer. Nature. 1985;316(6031):823-6.

7. Bologna M, Festuccia C, Muzi P, Biordi L, Ciomei M. Bombesin stimulates growth of human prostatic cancer cells in vitro. Cancer. 1989;63(9):1714-20.

8. Ramos-Alvarez I, Moreno P, Mantey SA, Nakamura T, Nuche-Berenguer B, Moody TW, et al. Insights into bombesin receptors and ligands: highlighting recent advances. Peptides. 2015:72:128-44.

9. Moreno P, Ramos-Alvarez I, Moody TW, Jensen RT. Bombesin related peptides/receptors and their promising therapeutic roles in cancer imaging, targeting and treatment. Expert Opin Ther Targets. 2016;20(9):1055-73.

10. Markwalder R, Reubi JC. Gastrin-releasing peptide receptors in the human prostate: relation to neoplastic transformation. Cancer Res. 1999;59(5):1152-9.

11. Van de Wiele C, Dumont F, Vanden Broecke R, Oosterlinck W, Cocquyt V. Serreyn R, et al. Technetium-99m RP527, a GRP analogue for visualisation of GRP receptor-expressing malignancies: a feasibility study. Eur J Nucl Med. 2000;27(11):1694-9.

12. Scopinaro F, De Vincentis G, Varvarigou AD, Laurenti C, lori F, Remediani S, et al. $99 \mathrm{mTc}$-bombesin detects prostate cancer and invasion of pelvic lymph nodes. Eur J Nucl Med Mol Imaging. 2003;30(10):1378-82.

13. Cescato R, Maina T, Nock B, Nikolopoulou A, Charalambidis D, Piccand V, et al. Bombesin receptor antagonists may be preferable to agonists for tumor targeting. J Nucl Med. 2008;49(2):318-26.

14. Mansi $\mathrm{R}$, Minamimoto $\mathrm{R}$, Macke $\mathrm{H}$, lagaru $\mathrm{AH}$. Bombesin-targeted PET of prostate cancer. J Nucl Med. 2016:57(Suppl 3):67S-72S.

15. lagaru A. Will GRPR compete with PSMA as a target in prostate cancer? J Nucl Med. 2017:58(12):1883-4.

16. Gourni E, Mansi R, Jamous M, Waser B, Smerling C, Burian A, et al. Nterminal modifications improve the receptor affinity and pharmacokinetics of radiolabeled peptidic gastrin-releasing peptide receptor antagonists: examples of 68Ga- and 64Cu-labeled peptides for PET imaging. J Nucl Med. 2014;55(10):1719-25.

17. Icrp. Radiation dose to patients from radiopharmaceuticals. Addendum 4 to ICRP Publication 53. ICRP Publication 106. Approved by the Commission in October 2007. Ann ICRP. 2008;38(1-2):1-197.

18. Roach M 3rd, Hanks G, Thames H Jr, Schellhammer P, Shipley WU, Sokol GH et al. Defining biochemical failure following radiotherapy with or without hormonal therapy in men with clinically localized prostate cancer: recommendations of the RTOG-ASTRO Phoenix consensus conference. Int J Radiat Oncol Biol Phys. 2006:65(4):965-74.

19. Bettinardi V, Presotto L, Rapisarda E, Picchio M, Gianolli L, Gilardi MC. Physical performance of the new hybrid PETCT Discovery-690. Med Phys. 2011;38(10):5394-411.

20. Gnesin S, Mitsakis P, Cicone F, Deshayes E, Dunet V, Gallino AF, et al. First inhuman radiation dosimetry of (68)Ga-NODAGA-RGDyK. EJNMMI Res. 2017;7(1):43. 
21. Basic anatomical and physiological data for use in radiological protection. reference values. A report of age- and gender-related differences in the anatomical and physiological characteristics of reference individuals. ICRP Publication 89. Ann ICRP. 2002;32(3-4):5-265.

22. Stabin MG, Siegel JA. RADAR dose estimate report: a compendium of radiopharmaceutical dose estimates based on OLINDA/EXM version 2.0. J Nucl Med. 2018;59(1):154-60.

23. Segars JP. Development and application of the new dynamic NURBSbased cardiac-torso (NCAT) phantom [dissertation]. In: University of North Carolina; 2001.

24. The 2007 Recommendations of the International Commission on Radiological Protection. ICRP publication 103. Ann ICRP. 2007;37(2-4):1-332.

25. Scopinaro F, Varvarigou AD, Ussof W, De Vincentis G, Sourlingas TG, Evangelatos GP, et al. Technetium labeled bombesin-like peptide: preliminary report on breast cancer uptake in patients. Cancer Biother Radiopharm. 2002;17(3):327-35.

26. Shariati F, Aryana K, Fattahi A, Forghani MN, Azarian A, Zakavi SR, et al. Diagnostic value of $99 \mathrm{mT}$ c-bombesin scintigraphy for differentiation of malignant from benign breast lesions. Nucl Med Commun. 2014;35(6):620-5.

27. Morgat C, MacGrogan G, Brouste V, Velasco V, Sevenet N, Bonnefoi H, et al. Expression of gastrin-releasing peptide receptor in breast cancer and its association with pathologic, biologic, and clinical parameters: a study of 1,432 primary tumors. J Nucl Med. 2017;58(9):1401-7.

28. Van de Wiele C, Dumont F, Dierckx RA, Peers SH, Thornback JR, Slegers G, et al. Biodistribution and dosimetry of (99m)Tc-RP527, a gastrin-releasing peptide (GRP) agonist for the visualization of GRP receptor-expressing malignancies. J Nucl Med. 2001;42(11):1722-7.

29. Santos-Cuevas CL, Ferro-Flores G, Arteaga de Murphy C, Pichardo-Romero PA. Targeted imaging of gastrin-releasing peptide receptors with $99 \mathrm{mTC}$ EDDA/HYNIC-[Lys3]-bombesin: biokinetics and dosimetry in women. Nucl Med Commun. 2008;29(8):741-7.

30. Roivainen A, Kahkonen E, Luoto P, Borkowski S, Hofmann B, Jambor I, et al. Plasma pharmacokinetics, whole-body distribution, metabolism, and radiation dosimetry of $68 \mathrm{Ga}$ bombesin antagonist BAY 86-7548 in healthy men. J Nucl Med. 2013;54(6):867-72.

31. Wieser G, Mansi R, Grosu AL, Schultze-Seemann W, Dumont-Walter RA, Meyer PT, et al. Positron emission tomography (PET) imaging of prostate cancer with a gastrin releasing peptide receptor antagonist-from mice to men. Theranostics. 2014;4(4):412-9.

32. Sah BR, Burger IA, Schibli R, Friebe M, Dinkelborg L, Graham K, et al. Dosimetry and first clinical evaluation of the new 18F-radiolabeled bombesin analogue BAY 864367 in patients with prostate cancer. J Nucl Med. 2015;56(3):372-8

33. Zhang J, Li D, Lang L, Zhu Z, Wang L, Wu P, et al. 68Ga-NOTA-aca-BBN(7-14) PET/CT in healthy volunteers and glioma patients. J Nucl Med. 2016;57(1):9-14.

34. Zhang J, Niu G, Fan X, Lang L, Hou G, Chen L, et al. PET using a GRPR antagonist (68)Ga-RM26 in healthy volunteers and prostate cancer patients. J Nucl Med. 2018;59(6):922-8.

35. Cristy M, Eckerman KF.Specific absorbed fractions of energy at various ages from internal photon sources.: Oak Ridge National Lab., TN (USA); 1987. Report No.: ORNL/TM-8381/N1-V7;

36. Stabin MG, Sparks RB, Crowe E. OLINDA/EXM: the second-generation personal computer software for internal dose assessment in nuclear medicine. J Nucl Med. 2005;46(6):1023-7.

37. Mitsakis P, Zilli T, Kosinski M, Delage J, Maecke H, Mansi R, et al. A direct comparison study of Ga-68-NODAGA-MJ9 (MJ9, Bombesin) to F-18-FCH (FCH) in recurrent prostate cancer. Eur J Nucl Med Mol Imaging. 2015;42(1):S124.

38. Kahkonen E, Jambor I, Kemppainen J, Lehtio K, Gronroos TJ, Kuisma A, et al. In vivo imaging of prostate cancer using [68Ga]-labeled bombesin analog BAY86-7548. Clin Cancer Res. 2013;19(19):5434-43.

39. Taieb D, Foletti JM, Bardies M, Rocchi P, Hicks RJ, Haberkorn U. PSMAtargeted radionuclide therapy and salivary gland toxicity: why does it matter? J Nucl Med. 2018;59(5):747-8.

40. Dalm SU, Bakker IL, de Blois E, Doeswijk GN, Konijnenberg MW, Orlandi F, et al. 68Ga/177Lu-NeoBOMB1, a novel radiolabeled GRPR antagonist for Theranostic use in oncology. J Nucl Med. 2017;58(2):293-9.

41. Eom K, Chie EK, Kim K, Jang JJ, Kim SW, Oh DY, et al. Postoperative chemoradiotherapy following pancreaticoduodenectomy. Impact of dosevolumetric parameters on the development of diabetes mellitus. Strahlenther Onkol. 2013;189(9):753-8
42. Jingu K, Tanabe T, Nemoto K, Ariga H, Umezawa R, Ogawa Y, et al. Intraoperative radiotherapy for pancreatic cancer: 30-year experience in a single institution in Japan. Int J Radiat Oncol Biol Phys. 2012;83(4):e507-11.

43. Herrmann K, Bluemel C, Weineisen M, Schottelius M, Wester HJ, Czernin J, et al. Biodistribution and radiation dosimetry for a probe targeting prostatespecific membrane antigen for imaging and therapy. J Nucl Med. 2015; 56(6):855-61.

44. Afshar-Oromieh A, Hetzheim H, Kratochwil C, Benesova M, Eder M, Neels OC, et al. The Theranostic PSMA ligand PSMA-617 in the diagnosis of prostate cancer by PET/CT: biodistribution in humans, radiation dosimetry, and first evaluation of tumor lesions. J Nucl Med. 2015;56(11):1697-705.

45. Afshar-Oromieh A, Hetzheim H, Kubler W, Kratochwil C, Giesel FL, Hope TA, et al. Radiation dosimetry of (68)Ga-PSMA-11 (HBED-CC) and preliminary evaluation of optimal imaging timing. Eur J Nucl Med Mol Imaging. 2016; 43(9):1611-20.

46. Pfob CH, Ziegler S, Graner FP, Kohner M, Schachoff S, Blechert B, et al. Biodistribution and radiation dosimetry of (68)Ga-PSMA HBED CC-a PSMA specific probe for PET imaging of prostate cancer. Eur J Nucl Med Mol Imaging. 2016;43(11):1962-70.

47. Walker RC, Smith GT, Liu E, Moore B, Clanton J, Stabin M. Measured human dosimetry of 68Ga-DOTATATE. J Nucl Med. 2013;54(6):855-60.

48. Josefsson A, Hobbs RF, Ranka S, Schwarz BC, Plyku D, de Carvalho JWA, et al. Comparative dosimetry for (68)Ga-DOTATATE: impact of using updated ICRP phantoms, S values and tissue weighting factors. J NuCl Med. 2018;59(8):1281-8.

\section{Submit your manuscript to a SpringerOpen ${ }^{\odot}$ journal and benefit from:}

- Convenient online submission

Rigorous peer review

- Open access: articles freely available online

- High visibility within the field

- Retaining the copyright to your article

Submit your next manuscript at $>$ springeropen.com 